\title{
BMJ Open Real-time utilisation of administrative data in the ED to identify older patients at risk: development and validation of the Dynamic Silver Code
}

\author{
Daniela Balzi, ${ }^{1}$ Giulia Carreras, ${ }^{2}$ Francesco Tonarelli, ${ }^{2}$ Luca Degli Esposti, ${ }^{3}$ \\ Paola Michelozzi, ${ }^{4}$ Andrea Ungar, ${ }^{2,5}$ Luciano Gabbani, ${ }^{6}$ Enrico Benvenuti, ${ }^{7}$ \\ Giancarlo Landini, ${ }^{8}$ Roberto Bernabei, ${ }^{9}$ Niccolò Marchionni, ${ }^{2,10}$ Mauro Di Bari (id ${ }^{2,5}$
}

To cite: Balzi D, Carreras G, Tonarelli F, et al. Real-time utilisation of administrative data in the ED to identify older patients at risk: development and validation of the Dynamic Silver Code. BMJ Open 2019;9:e033374. doi:10.1136/ bmjopen-2019-033374

- Prepublication history for this paper is available online. To view these files, please visit the journal online (http://dx.doi org/10.1136/bmjopen-2019033374).

Received 03 August 2019 Revised 09 November 2019 Accepted 20 November 2019

Check for updates

(c) Author(s) (or their employer(s)) 2019. Re-use permitted under CC BY-NC. No commercial re-use. See rights and permissions. Published by BMJ.

For numbered affiliations see end of article.

Correspondence to Professor Mauro Di Bari; mauro.dibari@unifi.it

\section{ABSTRACT}

Objective Identification of older patients at risk, among those accessing the emergency department (ED), may support clinical decision-making. To this purpose, we developed and validated the Dynamic Silver Code (DSC), a score based on real-time linkage of administrative data. Design and setting The 'Silver Code National Project (SCNP)', a non-concurrent cohort study, was used for retrospective development and internal validation of the DSC. External validation was obtained in the 'Anziani in DEA (AIDEA)' concurrent cohort study, where the DSC was generated by the software routinely used in the ED.

Participants The SCNP contained 281321 records of 180 079 residents aged $75+$ years from Tuscany and Lazio, Italy, admitted via the ED to Internal Medicine or Geriatrics units. The AIDEA study enrolled 4425 subjects aged $75+$ years (5217 records) accessing two EDs in the area of Florence, Italy.

Interventions None.

Outcome measures Primary outcome: 1-year mortality. Secondary outcomes: 7 and 30-day mortality and 1-year recurrent $E D$ visits.

Results Advancing age, male gender, previous hospital admission, discharge diagnosis, time from discharge and polypharmacy predicted 1-year mortality and contributed to the DSC in the development subsample of the SCNP cohort. Based on score quartiles, participants were classified into low, medium, high and very high-risk classes. In the SCNP validation sample, mortality increased progressively from 144 to 367 per 1000 person-years, across DSC classes, with HR $(95 \% \mathrm{Cl})$ of $1.92(1.85$ to 1.99), 2.71 (2.61 to 2.81) and 5.40 (5.21 to 5.59) in class II, III and IV, respectively versus class I ( $p<0.001)$. Findings were similar in AIDEA, where the DSC predicted also recurrent ED visits in 1 year. In both databases, the DSC predicted 7 and 30-day mortality.

Conclusions The DSC, based on administrative data available in real time, predicts prognosis of older patients and might improve their management in the ED.

\section{INTRODUCTION}

At the end of the disease era, when medical care is mostly directed towards management of chronic multimorbidity
Strengths and limitations of this study

- The Dynamic Silver Code combines in real time administrative data available in all Italian regions, to automatically produce a score predicting 1-year mortality and other health outcomes in older persons accessing the emergency department (ED).

- The tool was developed retrospectively and initially validated in a large, representative cohort of patients aged 75+ years; it was further validated in a new cohort of subjects prospectively recruited, where the tool was available in the software routinely used for clinical management of patients in the ED.

- We did not include predictors such as data on outpatient services, functional status and census, nor outcomes such as functional impairment, cognitive decline and institutionalisation.

or non-disease-specific complaints in older persons, ${ }^{1}$ a gear shift in the scope of, and the approach to, prognostic assessment is necessary. Besides survival, other goals should be pursued as outcomes of disease prevention and treatment, such as relief of symptoms, maintenance of personal autonomy and preservation of quality of life, all of which may be targets of prognostic evaluation. ${ }^{2}$ Focusing on one single disease is of limited value, when other coexistent illnesses, age-related physiological changes and non-biological determinants of health may all affect prognosis. Patient's preferences and future perspectives must be valued: many older patients at the end of their life receive futile therapies for minor conditions, ${ }^{3}$ whereas others with a reasonable disability-free life expectancy fail to receive appropriate treatments just because they are considered too old. ${ }^{4}$

Prognostic tools have the potential to help clinicians optimise the benefit/burden ratio of medical interventions ${ }^{2}$ and support their 
decision-making ${ }^{5}$; they may prove useful also in the health policy arena, to perform risk adjustment when comparing clinical interventions or healthcare models. ${ }^{25}$ Administrative data are increasingly used to this purpose, because of their variety, availability, low cost and accuracy. ${ }^{7-9}$ Such tools have been applied to screen inpatients, ${ }^{10} 11$ outpatients ${ }^{12}$ and free-living subjects ${ }^{512} 13$ for mortality, hospitalisation or disease-specific outcomes, aiming for personalised cures. ${ }^{14-16}$

We have previously described the Silver Code (SC), which combines administrative data into a score predicting 1-year survival in subjects aged $75+$ years, admitted to the hospital via the emergency department (ED). ${ }^{17} 18$ The Dynamic SC (DSC) presented here is an evolution of the original score, developed from a large administrative data set and then applied prospectively in a new sample. Whereas the original SC was based on one single moment of observation, the DSC considers, for each individual, the dynamics of events occurring across time. The new tool has been implemented into the software routinely used in the ED of several hospitals in Tuscany, Italy, to provide automated, real-time risk stratification of older patients.

\section{METHODS}

The DSC was obtained following the same general approach used for the SC, that is, combining into a score variables from healthcare administrative archives, to predict long-term survival of older persons admitted to the hospital. Compared with the SC, the cohort used to develop and validate the DSC was much larger and representative of the general older population. Moreover, important computational differences were introduced and external validation in a completely new cohort was obtained.

\section{Study design and data source}

Two different studies contributed to the present investigation. The first was the 'Silver Code National Project (SCNP)', which was sponsored by the Centre for Disease Control of the Italian Ministry of Health in $2008 .{ }^{19}$ The second was represented by the 'Anziani in DEA (AIDEA)' (standing for 'Older Persons in the ED') study, jointly sponsored by the Italian Ministry of Health and by the Tuscany Region in 2010 (RF-2010-2321801). The SCNP was a non-concurrent cohort study, whereas AIDEA followed a prospective cohort study design.

The SCNP database, ${ }^{19}$ representing the primary data source for the development and initial validation of the DSC, was obtained from the administrative archives of two regions in Italy, Tuscany and Lazio, which deliver healthcare services to a total population of more than 9.6 million persons. The archives included data on demographics, hospitalisations, drug prescriptions and deaths of beneficiaries aged 75+ years, who had been admitted via the ED to hospitals in the two regions between April 2004 and December 2009. Data were linked using a numeric unique identifier, which allowed records anonymisation before data processing to preserve beneficiaries' confidentiality. Universal healthcare coverage in Italy allows completeness and comprehensiveness of the information contained in these databases, which have been used in previous epidemiological studies. ${ }^{17} 20$ The Italian Ministry of Health reported that Tuscany archives are $100 \%$ complete and $95 \%$ accurate. ${ }^{21} 22$

Further validation of the score developed from the SCNP was subsequently obtained in a different sample, assembled in the AIDEA study, which was conducted in the ED of two hospitals in Florence, Italy, the Azienda Ospedaliero-Universitaria Careggi (AOUC), an academic tertiary hospital, and the Ospedale S Maria Annunziata (OSMA), a large community hospital. Enrolment was consecutively conducted between June and August 2016 and again between February and March 2017 in the AOUC, and between August and September 2016 in the OSMA, for a total of 22 weeks. In AIDEA, an application generating the DSC was incorporated into the software routinely used in the ED of the hospitals of the Tuscany Region: as soon as an eligible patient was triaged, the repository of healthcare data of the Local Health Unit was queried to provide, thanks to on-demand linkage of the different archives involved, the information required to obtain the DSC. The score was then in real time calculated and shown, together with the corresponding risk class, onto the computer screen. The lag time between occurrence of events contributing to the DSC (hospitalisations and drug prescriptions) and their registration in the healthcare data repository was approximately 2 weeks.

\section{Participants' selection}

The SCNP selected only records of subjects aged 75+ years, residing in the area where the study was conducted, who consecutively accessed the ED of the participating hospitals in the specified time windows and were eventually admitted to Internal Medicine or Geriatrics wards. Conversely, the AIDEA study enrolled all the residents aged $75+$ years consecutively accessing the ED in the specified time periods, independent of the outcome (hospitalisation or discharge) of their access to the ED.

\section{Patient and public involvement}

Patients or the public were not involved in the design or conduct of our research, partially because of its retrospective nature. Patients' associations will be involved in the upcoming, large-scale application of the DSC in hospitals of the Tuscany Region. Reporting was provided as requested by the funding institutions. Dissemination to the public was obtained through lay press.

\section{Analytical procedures}

Statistical analysis was performed with SPSS for Mac V.25 (IBMCorp., Armonk, NY, USA), STATA V.15.1 (StataCorp. 2017. Stata Statistical Software: Release 15. College Station, TX: StataCorp LLC) and R V.3.5.0 (R Core Team, 2018). 
A total of 281321 records were available in the SCNP database to create the DSC and test its validity. The $\chi^{2}$ was used to test differences in relative frequencies and to identify bivariate predictors of death, taking into account trends as appropriate.

The sample was randomly split into a development and a validation subsample. In the first subsample, a Cox proportional hazards model was fit to estimate the association, expressed as HR with 95\% CI of demographics and other variables on 1-year all-cause mortality risk. Variables initially considered, by definition limited to those available prior to the index ED visit, included age, gender, number of drugs prescribed in the previous 3 months as resulting from pharmacy claims (categorised as $0-3$, 4-5, 6-8 and 9+), days from previous hospital admission (no admission, 30-180 days, 0-30 days) and its associated main diagnostic group (cancer, respiratory disease, cardiovascular disease and other conditions), which were selected as the most frequently observed, in the study cohort, among those included in the International Classification of Diseases, Ninth Revision (ICD-9) classification. Compared with the original version of the SC, previous admission to a day hospital was not considered, because availability and utilisation of day hospital service are not consistent across regions in Italy. Marital status information was also omitted, because it was frequently missing in the discharge summary and in preliminary analyses it contributed marginally to the prediction of death. Different from the SC, repeated hospitalisations were taken into account to dynamically update patient's information at each new hospital admission. To this purpose, data were arranged in order to have one observation per event or time interval, and the counting process approach proposed by Andersen and $\mathrm{Gill}^{23}$ was applied: this is a generalisation of Cox model, which assumes that the correlation between event times for a person can be explained by past events. Thus, we made the assumption that correlations among events for each individual were captured by appropriate time-dependent covariates.

We evaluated the adherence of predictors to the assumption of proportional hazards and tested for multicollinearity comparing different models in terms of Akaike information criteria. ${ }^{24}$ We then assigned each risk factor a score, calculated as the ratio, rounded to the nearest integer, between the regression $b$ coefficient for that variable and the smallest significant $b$ coefficient $\left(b_{0}\right)$ in the Cox model. We finally computed the DSC as a summary score, by adding the points individually assigned to each risk factor. Four prognostic classes were then created from DSC quartiles.

In the validation data set, Harrell's $\mathrm{C}$ index of concordance was applied to evaluate model performance, as a measure of the predictive power of Cox regression model. ${ }^{25}$ Furthermore, the ability of DSC classes to predict 1-year mortality was analysed after adjusting for region of enrolment and ICD-9 coded principal diagnosis at discharge after the index hospitalisation. External validity of the DSC was performed in the AIDEA data set, using Cox regression models and Harrell's C index of concordance to predict 1-year mortality and the risk of recurrent ED access after a first hospital admission.

Additional analyses were performed to verify the ability of the DSC to predict 7 and 30-day mortality, two outcomes that are more immediate and potentially of greater clinical interest in the perspective of application of the tool in the ED. Also these analyses were adjusted for main diagnostic group at discharge and region of enrolment.

A two-tailed $p$ value less than 0.05 was considered statistically significant.

\section{RESULTS}

\section{Participants in the SCNP}

Out of the 281321 records in the SCNP, 180079 (64.01\%) pertained to a single hospitalisation, the remaining to patients with multiple hospital admissions in the study period. The random split assigned 90039 patients to the development and 90040 to the validation subsample, with 140716 and 140605 records, respectively. As shown in table 1, baseline characteristics of participants on their first hospital admission were comparable between the two subsamples.

\section{Predictors of 1-year mortality}

From hospital admission through the following year, a total of 42434 deaths were recorded; mortality was comparable in the development (21 250/90 039, 23.6\%) and the validation (21 184/90 040, 23.5\%) subsamples. In the development sample, bivariate predictors of death were older age ( $75-79$ years: $16.4 \%, 80-84$ years: $20.5 \%$, 85 + years: $31.9 \% ; \mathrm{p}=0.001$ ), gender (men: $24.8 \%$, women: $22.7 \%$; $\mathrm{p}<0.001$ ), previous hospital admission with its corresponding main discharge diagnosis (no admission: 22.1\%, cardiovascular disease: $23.5 \%$, cancer: $49.1 \%$, respiratory disease: $30.8 \%$, other diagnoses: $30.2 \%$; $\mathrm{p}<0.001$ ), days from previous hospital admission (1-30 days: $34.5 \%, 31-180$ days: $28.5 \%, \mathrm{p}<0.001)$ or taking more drugs prior to the index ED admission (0-3: 22.6\%, 4-5: 22.9\%, 6-8: 23.3\%, 9+: 26.2\%; $\mathrm{p}<0.001)$.

\section{Risk models}

Table 2 shows the results of Cox proportional hazards regression model in the SCNP development subsample. All the variables considered were significant predictors of 1-year mortality. Because the diagnostic groups of 'cardiovascular disease' and 'others' obtained similar HRs, they were combined into a single category, contrasted with 'no previous hospital admission', 'cancer' and 'respiratory disease'. The predictors 'days from the previous hospital admission' and the associated 'main diagnostic group' showed some multicollinearity, but the models with only one of those variables performed worse in terms of Akaike information criteria: therefore, both variables were maintained in the final model. All predictors satisfied the assumption of proportional hazards. 
Table 1 Baseline characteristics of participants on their first hospital admission, in the entire sample and in the development and validation subsamples. The $p$ value reported refers to the $\chi^{2}$ test, for trend when appropriate

\begin{tabular}{|c|c|c|c|c|c|c|c|}
\hline \multirow[b]{2}{*}{ Variable } & \multicolumn{2}{|c|}{$\begin{array}{l}\text { Overall } \\
(n=180079)\end{array}$} & \multicolumn{2}{|c|}{$\begin{array}{l}\text { Development subsample } \\
(\mathrm{n}=90039)\end{array}$} & \multicolumn{2}{|c|}{$\begin{array}{l}\text { Validation subsample } \\
(\mathrm{n}=90040)\end{array}$} & \multirow[t]{2}{*}{$P$ value } \\
\hline & $\mathbf{n}$ & $\%$ & $\mathbf{n}$ & $\%$ & $\mathbf{n}$ & $\%$ & \\
\hline \multicolumn{7}{|l|}{ Age (years) } & 0.348 \\
\hline $75-79$ & 52196 & 29.0 & 25974 & 28.9 & 26222 & 29.1 & \\
\hline $80-84$ & 60205 & 33.4 & 30221 & 33.6 & 29984 & 33.3 & \\
\hline $85+$ & 67678 & 37.6 & 33844 & 37.6 & 33834 & 37.6 & \\
\hline \multicolumn{7}{|l|}{ Gender } & 0.639 \\
\hline Male & 77803 & 43.2 & 38852 & 43.2 & 38951 & 43.3 & \\
\hline Female & 102276 & 56.8 & 51187 & 56.9 & 51089 & 56.7 & \\
\hline \multicolumn{7}{|c|}{ Number of drugs in previous 3 months } & 0.268 \\
\hline $0-3$ & 57859 & 32.1 & 28995 & 32.2 & 28864 & 32.1 & \\
\hline $4-5$ & 38405 & 21.3 & 19322 & 21.5 & 19083 & 21.2 & \\
\hline $6-8$ & 46754 & 26.0 & 23222 & 25.8 & 23532 & 26.1 & \\
\hline $9+$ & 37061 & 20.6 & 18500 & 20.6 & 18561 & 20.6 & \\
\hline \multicolumn{7}{|c|}{$\begin{array}{l}\text { Main diagnostic group in previous } \\
\text { (6 months) hospital admission }\end{array}$} & 0.773 \\
\hline $\begin{array}{l}\text { No previous hospital } \\
\text { admission }\end{array}$ & 146562 & 81.4 & 73241 & 81.3 & 73321 & 81.4 & \\
\hline Cardiovascular disease & 11206 & 6.2 & 5537 & 6.15 & 5669 & 6.3 & \\
\hline Cancer & 3954 & 2.2 & 1955 & 2.2 & 1999 & 2.2 & \\
\hline Respiratory disease & 3171 & 1.8 & 1585 & 1.8 & 1586 & 1.8 & \\
\hline Others & 15186 & 8.4 & 7721 & 8.6 & 7465 & 8.3 & \\
\hline \multicolumn{7}{|c|}{ Days from previous (6 months) hospital admission } & 0.156 \\
\hline $\begin{array}{l}\text { No previous hospital } \\
\text { admission }\end{array}$ & 146562 & 81.4 & 73241 & 81.3 & 73321 & 81.4 & \\
\hline $31-180$ & 23374 & 13.0 & 11793 & 13.1 & 11581 & 12.9 & \\
\hline $0-30$ & 10143 & 5.6 & 5005 & 5.6 & 5138 & 5.7 & \\
\hline
\end{tabular}

The smallest significant b coefficient in the Cox model resulted to be associated with four to five drugs prescribed in the previous 3 months $\left(b_{0}=0.0364\right)$. Thus, each significant predictor was assigned a score by rounding the ratio between the corresponding $b$ coefficient in the regression model and $\mathrm{b}_{0}$ up to the nearest integer (table 2). The DSC was finally calculated as summation of all scores.

Participants were classified into low, medium, high and very high-risk classes, based on DSC quartiles. Oneyear risk of death increased significantly from the first to the fourth DSC class, with almost identical rates and HRs in the two subsamples (table 3). In the validation subsample, the performance of the risk scoring system, assessed with Harrell's C index, was 0.668 (95\% CI 0.665 to 0.672 ). The ability of the DSC to predict 1-year mortality persisted controlling for main diagnostic group at discharge after the index hospitalisation and region of enrolment (Tuscany vs Lazio), as shown by HR $(95 \% \mathrm{CI})$ of 1.93 (1.88 to 1.98), 2.71 (2.64 to 2.78) and 5.00 (4.88 to 5.13) for class II, III and IV, respectively, compared with class I $(\mathrm{p}<0.001)$ (figure 1$)$.

\section{External validity}

External validity of the DSC was ascertained in the AIDEA sample, which included 5217 records for 4425 subjects, of whom 1292 died and 465 had a new ED admission within 1 year. Mortality increased progressively across DSC classes, with rates of 106, 197, 303 and 412 per 1000 person-years from class I through class IV, and HR $(95 \% \mathrm{CI})$ of 2.06 (1.68 to 2.53 ), 3.32 (2.74 to 4.03 ) and 5.28 (4.37 to 6.39 ) in class II, III and IV, respectively versus class I ( $\mathrm{p}<0.001)$. Harrell's C index for mortality was 0.660 (95\% CI 0.641 to 0.678). Also 1-year risk of recurrent ED access increased significantly across DSC classes, with rates of 69, 93, 89 and 139 per 1000 person-years from class I through class IV, and HR (95\% CI) of 1.46 (1.11 to 1.93$), 1.45$ (1.10 to $1.92)$ and 2.60 (1.99 to 3.40) in class II, III and IV, respectively versus class $I(p<0.001)$. For recurrent ED access, Harrell's C index was 0.604 (95\% CI 0.573 to 0.634 ).

\section{Prediction of short-term mortality}

The DSC predicted also 7 and 30-day mortality in both databases. In the SCNP database as a whole, 20297 and 
Table 2 Multivariable b coefficients, obtained from Cox regression model predicting 1-year death, in the 90039 participants in the development subsample, with scores associated

\begin{tabular}{clcc}
\hline Variable & b coefficient & P value & Score \\
\hline Age (years) & & & \\
$75-79$ & Ref & & 0 \\
$80-84$ & 0.2871 & $<0.001$ & 8 \\
$85+$ & 0.8259 & $<0.001$ & 23 \\
Gender & & & \\
Female & Ref & & 0 \\
Male & 0.1875 & $<0.001$ & 5 \\
\hline
\end{tabular}

Number of drugs in

previous 3 months

\begin{tabular}{|c|c|c|c|}
\hline $0-3$ & Ref & & 0 \\
\hline $4-5$ & 0.0364 & 0.0320 & 1 \\
\hline $6-8$ & 0.0732 & $<0.001$ & 2 \\
\hline $9+$ & 0.2173 & $<0.001$ & 6 \\
\hline \multicolumn{4}{|c|}{$\begin{array}{l}\text { Main diagnostic group in previous } \\
\text { (6 months) hospital admission }\end{array}$} \\
\hline No admission & Ref & & 0 \\
\hline $\begin{array}{l}\text { Cardiovascular } \\
\text { disease/others }\end{array}$ & 0.6944 & $<0.001$ & 19 \\
\hline Cancer & 1.5218 & $<0.001$ & 42 \\
\hline Respiratory disease & 1.0357 & $<0.001$ & 28 \\
\hline \multicolumn{4}{|c|}{ Days from previous (6 months) hospital admission } \\
\hline No admission & Ref & & 0 \\
\hline $30-180$ & 0.2763 & $<0.001$ & 8 \\
\hline $0-30$ & 0.000 & & 0 \\
\hline
\end{tabular}

27812 participants died within 7 and 30 days, respectively, out of the 180079 enrolled. In AIDEA, the analysis on 7 and 30-day mortality included 4425 participants, of whom 102 and 345 died within 7 and 30 days, respectively. In both databases and for both follow-up times, shortterm mortality increased significantly across DSC classes

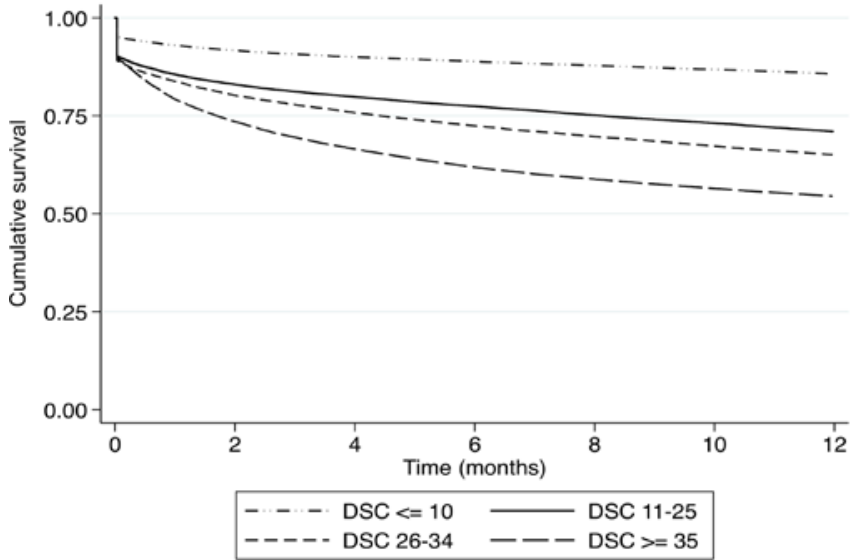

Figure 1 Survival curves for cumulative risk of death within 1 year after first hospitalisation by class of Dynamic Silver Code (DSC) in the validation sample $(n=90040)$. Cox proportional hazards regression, adjusting for region of residence and main discharge diagnostic group, with $\mathrm{p}$ for trend $<0.001$.

$(\mathrm{p}<0.001)$ (table 4). Harrell's C index was 0.623 (95\% CI 0.618 to 0.627 ) and 0.639 (95\% CI 0.635 to 0.643 ) for 7 and 30-day mortality, respectively, in the SCNP and 0.690 (95\% CI 0.619 to 0.761 ) and 0.683 (95\% CI 0.645 to 0.721 ) in AIDEA.

\section{DISCUSSION}

Using the SCNP large, representative cohort of older persons accessing the ED and then admitted to hospitals in two Italian regions, we developed the DSC, which combines simple variables, extracted from administrative databases, into a score predicting 1-year mortality. The score was validated against mortality in a random subset of the same cohort, and then its external validity was proven in the newly enrolled sample of the AIDEA study. Remarkably, whereas in the SCNP cohort the DSC was obtained from offline processing of consolidated archives, in AIDEA it was generated in real time on arrival of each eligible patient, thanks to an application implemented in

Table 3 One-year mortality and corresponding HRs by DSC class, separately in the development and validation subsamples

\begin{tabular}{|c|c|c|c|c|c|c|c|c|}
\hline \multirow[b]{2}{*}{$\begin{array}{l}\text { DSC class } \\
\text { (score) }\end{array}$} & \multicolumn{4}{|c|}{ Development subsample ( $n=90039)$} & \multicolumn{4}{|c|}{ Validation subsample $(n=90040)$} \\
\hline & Participants & Deaths & $\begin{array}{l}\text { Rate } \\
\text { (per 1000 } \\
\text { person-years) }\end{array}$ & $\begin{array}{l}\text { HR } \\
(95 \% \mathrm{Cl})\end{array}$ & Participants & Deaths & $\begin{array}{l}\text { Rate } \\
\text { (per } 1000 \\
\text { person-years) }\end{array}$ & $\begin{array}{l}\text { HR } \\
(95 \% \mathrm{Cl})\end{array}$ \\
\hline I $(\leq 10)$ & 29880 & 4303 & 144 & Ref & 29798 & 4291 & 144 & Ref \\
\hline II (11-25) & 32712 & 8127 & 248 & $\begin{array}{l}1.93 \\
\text { (1.86 to } 2.00)\end{array}$ & 32775 & 8082 & 247 & $\begin{array}{l}1.92 \\
\text { (1.85 to } 1.99)\end{array}$ \\
\hline IV $(\geq 35)$ & 10056 & 3640 & 362 & $\begin{array}{l}5.37 \\
\text { (5.18 to } 5.56)\end{array}$ & 10028 & 3685 & 367 & $\begin{array}{l}5.40 \\
\text { (5.21 to } 5.59)\end{array}$ \\
\hline Total & 90039 & 21250 & 236 & & 90040 & 21184 & 235 & \\
\hline
\end{tabular}

DSC, Dynamic Silver Code. 
Table 4 Prediction of 7 and 30-day mortality by DSC class in the complete SCNP and in the AIDEA databases

\begin{tabular}{|c|c|c|c|c|c|c|c|c|}
\hline \multirow[b]{3}{*}{$\begin{array}{l}\text { DSC } \\
\text { class } \\
\text { (score) }\end{array}$} & \multicolumn{4}{|l|}{ SCNP } & \multicolumn{4}{|l|}{ AIDEA } \\
\hline & \multicolumn{2}{|c|}{ 7-day mortality } & \multicolumn{2}{|c|}{ 30-day mortality } & \multicolumn{2}{|c|}{ 7-day mortality } & \multicolumn{2}{|c|}{ 30-day mortality } \\
\hline & $\begin{array}{l}\text { Rate } \\
\text { (per } 1000 \\
\text { person- } \\
\text { years) }\end{array}$ & $\begin{array}{l}\text { HR } \\
(95 \% \mathrm{Cl}) \text { * }\end{array}$ & $\begin{array}{l}\text { Rate } \\
\text { (per } 1000 \\
\text { person- } \\
\text { years) }\end{array}$ & $\begin{array}{l}\text { HR } \\
(95 \% \mathrm{Cl}) \text { * }\end{array}$ & $\begin{array}{l}\text { Rate } \\
\text { (per } 1000 \\
\text { person- } \\
\text { years) }\end{array}$ & $\begin{array}{l}\text { HR } \\
(95 \% \mathrm{Cl})\end{array}$ & $\begin{array}{l}\text { Rate } \\
\text { (per } 1000 \\
\text { person- } \\
\text { years) }\end{array}$ & $\begin{array}{l}\text { HR } \\
(95 \% \mathrm{Cl})\end{array}$ \\
\hline I $(\leq 10)$ & 64 & Ref & 81 & Ref & 8 & Ref & 28 & Ref \\
\hline III (26-34) & 144 & 2.41 (2.31 to 2.52 ) & 178 & 2.53 (2.43 to 2.62 ) & 22 & 2.73 (1.33 to 5.64$)$ & 84 & 3.17 (2.17 to 4.64$)$ \\
\hline IV $(\geq 35)$ & 189 & 3.30 (3.15 to 3.45$)$ & 234 & 3.98 (3.84 to 4.14$)$ & 45 & 5.57 (2.78 to 11.15$)$ & 136 & 5.58 (3.85 to 8.09$)$ \\
\hline
\end{tabular}

*Adjusted for main diagnostic group at discharge and region of enrolment (Tuscany vs Lazio).

AIDEA, Anziani in DEA; DSC, Dynamic Silver Code; SCNP, Silver Code National Project.

the software routinely used for patients' clinical management in the EDs of Tuscany Region.

In older persons, because of coexisting chronic comorbidities and diminished life expectancy, fully informed clinical decision-making requires adequate knowledge of patient's prognosis. In the presence of any given acute condition, comprehensive care planning should be carefully performed, by considering life expectancy, as well as premorbid functional and cognitive status. ${ }^{26}$ Nevertheless, accurate prognostic assessment of complex older patients is frequently overlooked in clinical practice, especially in the busy daily practice of an ED, where geriatric patients often arrive with non-specific complaints, such as worsening functional status, confusion, dizziness or fall. Their clinical presentation is frequently characterised not by a single, well-defined disease, but rather by an entangled combination of age-related changes, comorbidity, functional and cognitive impairment, polypharmacy and social problems. As a consequence, the risk of wrong triage, incorrect diagnosis and treatment, prolonged ED stay and inappropriate destination is substantial. ${ }^{27}$ Worsening disability, institutionalisation or death shortly after the ED access may be ultimate consequences. ${ }^{28}$

Instruments to screen older persons in the ED, based on comprehensive geriatric assessment, do exist, ${ }^{29}$ but are not used routinely in clinical practice, as they require some expertise and are time consuming. Thus, in spite of their inherent limitations, simple administrative data are increasingly explored as an attractive contribution to prognostic assessment, because they are accurate, objective and easily available at a low cost. ${ }^{7-9}$ Along this track, we have previously developed the $\mathrm{SC}$, which was shown to predict long-term mortality ${ }^{17} 18$ and hospitalisations of older persons in the $\mathrm{ED}^{18}$ in two different cohorts, with a discrimination ability comparable to that of other tools requiring face-to-face interview. ${ }^{18}$ Moreover, the SC allowed risk stratification when comparing the effects of different therapeutic approaches. ${ }^{1730}$ However, the algorithm to develop the SC relied only on the first ED admission, so that the score remained constant throughout the following observation time, independent of new hospitalisations or drug prescriptions. To overcome this limitation of the parent tool, the DSC was developed by taking into account each hospital admission as the unit of analysis. This would allow the score to reflect more closely the dynamics of risk status of older patients, changing after each hospitalisation or new drug prescription.

The variables contributing to the DSC can be all recognised as meaningful predictors of prognosis. In particular, the main driving forces in the DSC are advanced age and severe comorbidity, two well-known powerful prognostic factors. Yet, because short-term rehospitalisation usually indicates clinical instability, it is somewhat unexpected that, in the multivariable model reported in table 2, a previous hospital admission between 0 and 30 days had a b coefficient of zero, comparable to no admission. However, the Italian hospital discharge coding system does not allow distinguishing, among short-term rehospitalisations, those that might have been planned at the end of the index hospitalisation (eg, to complete diagnostics or treatments) from those occurring because of clinical instability.

The estimates we obtained are robust, because they were based on high-quality data from a large, randomly split population-based cohort, thus overcoming the problem of overestimation typical of small sample size data sets. ${ }^{31}$ The predictive ability of the tool persisted even after controlling for discharge diagnosis. As a further confirm, external validation was achieved in the new sample of the AIDEA study, whose participants might be hospitalised or not after the index ED access. It should be emphasised that the DSC predicted also short-term mortality and, at least in AIDEA, recurrent hospitalisations, outcomes for which it had not been created. As suggested by the lower short-term mortality rates reported in table 4, the AIDEA cohort was substantially healthier than the SCNP cohort: this is to be expected, as AIDEA enrolled also participants who were immediately discharged from the ED, without being hospitalised. Nevertheless, the incremental risk of death across DSC classes was comparable in the two studies. Moreover, short and longterm mortality rate figures in the AIDEA cohort compare well to those reported by Tanderup et al: in a Danish study 
on 3775 subjects aged 65+ years accessing the ED, 30-day and 1-year cumulative mortality increased progressively, from $2.2 \%$ to $10.6 \%$ and from $8 \%$ to $39 \%$, respectively, with the number of geriatric conditions (from 0 to 4), identified on the basis of comprehensive geriatric assessment. ${ }^{27}$ The similarity between Tanderup's and our estimates provides further, indirect support to the external validity of the DSC: the absolute mortality risk is indeed crucial, more than HR, to take appropriate decisions on treatment level.

In terms of Harrell's $\mathrm{C}$ index, the discrimination of the DSC was only moderate, similar in the internal and external validation cohorts. Thus, although predictive at the group level, its ability to predict prognosis at an individual level is suboptimal. A possible partial explanation for this finding is that the DSC might misclassify subjects defined at low risk, if they reached the ED with acute life-threatening conditions. Also nursing home residents with severe disability or dementia might be erroneously considered as at low risk by the DSC, if they had no recent hospital admissions: other administrative archives collecting data on nursing home services, which are expected to become promptly available at least in Tuscany, should eliminate this source of misclassification. On the other hand, comparably suboptimal performances have been reported for other tools, proposed in the literature for prognostic assessment in the $\mathrm{ED}$, such as the Identification of Seniors At Risk ${ }^{18}{ }^{29}$ (C statistics of 0.65 for 6-month mortality) or the Hospital Frailty Risk $\operatorname{Score}^{32}$ (C statistics of 0.60 for 30-day mortality), or widely used to drive clinical decisions in acute coronary syndromes, such as the TIMI risk score (C statistics of 0.65 for a 14-day composite endpoint). ${ }^{33}$ This may reflect the fact that, as pointed out by other authors, ${ }^{32}$ individual outcomes are inherently unpredictable in acute settings, even when risk status is well characterised at a cohort level. This does not detract from the clinical impact of the DSC and similar scores, which help delivery targeted interventions to groups of patients with specific characteristics, whereas, at an individual level, should be used to support, not to substitute clinical judgement.

A 2012 systematic review on prognostic indices for older adults ${ }^{2}$ reported only one article-our original publication on the parent instrument ${ }^{17}$ - that focused on ED triage of older persons using administrative data, but not in a real-time application. Although other more recent studies dealing with prognostic issues around older persons in an acute hospital setting can be found, none of them was developed for use in the ED nor proposed real-time linkage of administrative data. Thus, to the best of our knowledge, the DSC represents the first example in the literature of real-time utilisation of administrative data for prognostic purposes, at least in-but probably not limited to-older persons accessing the ED.

Several strengths of the DSC should be highlighted. First, it predicts short and long-term prognosis and risk of hospitalisation combining with a simple calculation a limited set of variables, obtained from administrative data: thus, it is objective and does not rely on patient's collaboration, which is sometime difficult to obtain in the presence of cognitive decline or communication barriers. Second, as the AIDEA study shows, it can be calculated in real time, being therefore immediately available to the ED staff as soon as a target patient is triaged, even before any clinical assessment and with no need of dedicated human resources to gather information. To our knowledge, this represents a unique example of clinical utilisation of administrative data, which might be easily replicated in other hospitals, at least in Italy. Third, it is a non-disease-specific tool, an important characteristic allowing its universal application in older patients, in whom multimorbidity and atypical symptom presentation make clinical and prognostic assessment challenging. Fourth, similar to other prognostic tools based on administrative data, it can be applied also to obtain risk adjustment in the healthcare policy arena: to our knowledge, no previous prognostic tools have been developed to pursue both clinical and epidemiological purposes.

Study limitations are to be acknowledged. The original SCNP data set is relatively old: however, the validity of the score was confirmed in the definitively more recent AIDEA cohort. The score was developed based on data obtained only in subjects admitted to Internal Medicine or Geriatrics units: nonetheless, its validity was confirmed in a completely different series, which included patients visiting the ED for a variety of reasons and most of times discharged from the ED. The data so far available did not consent considering other predictors (eg, claims for specialised visits or other services, or census data), neither different outcomes besides mortality, such as functional or cognitive decline and institutionalisation, which are highly relevant in geriatric patients. However, we are confident that the increasing availability of other administrative databases, as suggested above in reference to nursing home services, will allow incorporating a wider set of predictors as well as of endpoints in the next future.

In conclusion, the DSC, a simple prognostic tool based on administrative data, available in real time in the software used in the ED of Italian hospitals, offers a valid prognostic assessment of older patients, virtually at no additional costs, once the system has been set. This might support clinical decision-making and improve the quality of the care provided. Future studies are needed to assess whether these expectations will be satisfied.

\section{Author affiliations}

${ }^{1}$ Epidemiology, Azienda USL Toscana Centro, Firenze, Italy

${ }^{2}$ Research Unit of Medicine of Aging, Department of Clinical and Experimental Medicine, University of Florence, Firenze, Italy

${ }^{3}$ Health, Economics and Outcomes Research, CliCon, Ravenna, Italy

${ }^{4}$ Department of Epidemiology, Lazio Region, Roma, Italy

${ }^{5}$ Unit of Geriatrics - Geriatrics Intensive Care Unit, Department of Medicine and Geriatrics, Careggi Hospital, Firenze, Italy

${ }^{6}$ Unit of Geriatrics, Department of Medicine and Geriatrics, Careggi Hospital, Firenze, Italy

${ }^{7}$ Unit of Geriatrics, Department of Internal Medicine, Azienda USL Toscana Centro, Firenze, Italy

${ }^{8}$ Unit of Internal Medicine, Department of Internal Medicine, Azienda USL Toscana Centro, Firenze, Italy 
${ }^{9}$ Fondazione Policlinico Agostino Gemelli IRCCS, Rome, Italy

${ }^{10}$ Cardiothoracic and Vascular Department, Careggi Hospital, Firenze, Italy

Contributors DB conceived the study, conducted data management and analysis, and contributed to drafting of the manuscript. GC conducted data analysis and contributed to drafting of the manuscript. FT contributed to obtaining the data and drafting of the manuscript. LDE and PM obtained the data and contributed to data management. $\mathrm{AU}$ and $\mathrm{EB}$ contributed to obtaining the data and provided institutional support. LG and GL provided institutional support. RB and NM provided institutional support and contributed to developing the research question. MDB conceived the study, wrote the protocol, supervised the analyses and drafted the manuscript. All authors read and approved the final manuscript. All the authors were independent of the funders, had access to all the data and take responsibility for the integrity of the data and the accuracy of the data analysis.

Funding The 'Silver Code National Project' was funded by the Centre for Disease Control of the Italian Ministry of Health. The 'Anziani in DEA' study was jointly funded by the Italian Ministry of Health and by the Tuscany Region (RF-2010-2321801)

Disclaimer The funders had no role in study design, data collection and analysis, decision to publish or preparation of the manuscript.

Competing interests None declared.

Patient consent for publication Not required.

Ethics approval Following the Italian legislation on observational studies using administrative databases in place at the time of data acquisition, ethics committee approval and participants' subscription of informed consent was waived in the SCNP, because only anonymised administrative data were extracted. The protocol of the AIDEA study, which included also face-to-face interview (not reported in the present work), was approved by the Ethics Committee of the Azienda OspedalieroUniversitaria Careggi (976/13_AOUC).

Provenance and peer review Not commissioned; externally peer reviewed.

Data availability statement Data are available upon reasonable request.

Open access This is an open access article distributed in accordance with the Creative Commons Attribution Non Commercial (CC BY-NC 4.0) license, which permits others to distribute, remix, adapt, build upon this work non-commercially, and license their derivative works on different terms, provided the original work is properly cited, appropriate credit is given, any changes made indicated, and the use is non-commercial. See: http://creativecommons.org/licenses/by-nc/4.0/.

ORCID iD

Mauro Di Bari http://orcid.org/0000-0002-5514-0524

\section{REFERENCES}

1 Tinetti ME, Fried T. The end of the disease era. Am J Med 2004;116:179-85.

2 Yourman LC, Lee SJ, Schonberg MA, et al. Prognostic indices for older adults: a systematic review. JAMA 2012;307:182-92.

3 Walter LC, Covinsky KE. Cancer screening in elderly patients. JAMA 2001;285, 2750-

4 Mehta KM, Fung KZ, Kistler CE, et al. Impact of cognitive impairment on screening mammography use in older US women. Am J Public Health 2010;100:1917-23.

5 Wallace E, Stuart E, Vaughan N, et al. Risk prediction models to predict emergency hospital admission in community-dwelling adults: a systematic review. Med Care 2014;52:751-65.

6 Galvin R, Gilleit Y, Wallace E, et al. Adverse outcomes in older adults attending emergency departments: a systematic review and metaanalysis of the identification of seniors at risk (ISAR) screening tool. Age Ageing 2017;46:179-86.

7 Dagan N, Cohen-Stavi C, Leventer-Roberts M, et al. External validation and comparison of three prediction tools for risk of osteoporotic fractures using data from population based electronic health records: retrospective cohort study. BMJ 2017;i6755.

8 Albaba M, Cha SS, Takahashi PY. The elders risk assessment index, an electronic administrative database-derived frailty index, can identify risk of hip fracture in a cohort of community-dwelling adults. Mayo Clin Proc 2012;87:652-8.

9 Simpson AN, Wilmskoetter J, Hong I, et al. Stroke administrative severity index: using administrative data for 30-day poststroke outcomes prediction. J Comp Eff Res 2018;7:293-304.
10 Mahajan SM, Heidenreich P, Abbott B, et al. Predictive models for identifying risk of readmission after index hospitalization for heart failure: a systematic review. Eur $J$ Cardiovasc Nurs 2018;17:675-89.

11 Taylor RA, Pare JR, Venkatesh AK, et al. Prediction of in-hospital mortality in emergency department patients with sepsis: a local big data-driven, machine learning approach. Acad Emerg Med 2016;23:269-78.

12 Clegg A, Bates C, Young J, et al. Development and validation of an electronic frailty index using routine primary care electronic health record data. Age Ageing 2016;45:353-60.

13 Corrao G, Rea F, Di Martino M, et al. Developing and validating a novel multisource comorbidity score from administrative data: a large population-based cohort study from Italy. BMJ Open 2017; 7:e019503.

14 Davoudi A, Ozrazgat-Baslanti T, Ebadi A. Delirium prediction using machine learning models on predictive electronic health records data Proc IEEE Int Symp Bioinformatics Bioeng; 2018: 568-73.

15 Corey KM, Kashyap S, Lorenzi E, et al. Development and validation of machine learning models to identify high-risk surgical patients using automatically curated electronic health record data (Pythia): a retrospective, single-site study. PLoS Med 2018;15:e1002701.

16 Rahimian F, Salimi-Khorshidi G, Payberah AH, et al. Predicting the risk of emergency admission with machine learning: development and validation using linked electronic health records. PLoS Med 2018;15:e1002695

17 Di Bari M, Balzi D, Roberts AT, et al. Prognostic stratification of older persons based on simple administrative data: development and validation of the "Silver Code," to be used in emergency department triage. J Gerontol A Biol Sci Med Sci 2010;65:159-64.

18 Di Bari M, Salvi F, Roberts AT, et al. Prognostic Stratification of Elderly Patients in the Emergency Department: A Comparison Between the "Identification of Seniors at Risk" and the "Silver Code". J Gerontol A Biol Sci Med Sci 2012;67A:544-50.

19 Centro Nazionale per la Prevenzione e il Controllo delle Malattie. Modelli innovativi per la presa in carico del paziente anziano fragile nella transizione dall' ospedale al territorio e dal territorio all' ospedale: Case Management e qualità della vita. Available: http:// www.ccm-network.it/progetto.jsp? id=node/1353\&idP=740

20 Simonato L, Baldi I, Balzi D, et al. [Objectives, tools and methods for an epidemiological use of electronic health archives in various areas of Italy]. Epidemiol Prev 2008;32:5-14.

21 Ministero del Lavoro, della Salute e delle Politiche Sociali. Rapporto annuale sulla attività di ricovero ospedaliero-Anno, 2005. Available: http://www.ministerosalute.it/programmazione/sdo/sezDocumenti. jsp?id=148\&label=osp [Accessed 10 Apr 2019].

22 Ministero della Salute. Rapporto Annuale sull'attività di ricovero ospedaliero. Dati SDO

, 2019. Available: http://www.salute.gov.it/portale/temi/ p2 4.jsp?lingua=italiano\&tema=Assistenza, ospedale e territorio\&area=ricoveriOspedalieri [Accessed April 10, 2019].

23 Andersen PK, Gill RD. Cox's regression model for counting processes: a large sample study. Ann Statist 1982;10:1100-20.

24 Akaike $\mathrm{H}$. A new look at the statistical model identification. IEEE Trans Automat Contr 1974;19:716-23.

25 Harrell FE, Califf R, Pryor DB, et al. Evaluating the yield of medical tests. JAMA 1982;247:2543-6.

26 Gill TM. The central role of prognosis in clinical decision making. JAMA 2012;307:199-200.

27 Tanderup A, Lassen AT, Rosholm J-U, et al. Disability and morbidity among older patients in the emergency department: a Danish population-based cohort study. BMJ Open 2018;8:e023803.

28 Salvi F, Morichi V, Grilli A, et al. The elderly in the emergency department: a critical review of problems and solutions. Intern Emerg Med 2007;2:292-301.

29 McCusker J, Bellavance F, Cardin S, et al. Detection of older people at increased risk of adverse health outcomes after an emergency visit: the ISAR screening tool. J Am Geriatr Soc 1999;47:1229-37.

30 Di Bari M, Balzi D, Fracchia S, et al. Decreased usage and increased effectiveness of percutaneous coronary intervention in complex older patients with acute coronary syndromes. Heart 2014;100:1537-42

31 Royston P, Moons KGM, Altman DG, et al. Prognosis and prognostic research: developing a prognostic model. BMJ 2009;338:b604.

32 Gilbert T, Neuburger J, Kraindler J, et al. Development and validation of a hospital frailty risk score focusing on older people in acute care settings using electronic Hospital records: an observational study. The Lancet 2018;391:1775-82.

33 Antman EM, Cohen M, Bernink PJLM, et al. The TIMI risk score for unstable Angina/Non-ST elevation MI. JAMA 2000;284:835-42. 